\title{
The Role of Neutrophil Lymphocyte Ratio as a Major Adverse Cardiac Events Predictor and Its Correlation with Coronary Severity in Acute Coronary Syndrome Patients with Chronic Kidney Disease: A Case Control and Cross-Sectional Study
}

\author{
Suzanna Immanuel ${ }^{1}$, Eka Ginanjar²*(D), Fahrani Imanina Putri Nurtyas ${ }^{1}$, Ninik Sukartini ${ }^{1}$, Yusra Yusra ${ }^{1}$, Merci Monica B. R. \\ Pasaribu $^{1}$ \\ ${ }^{1}$ Department of Clinical Pathology, Faculty of Medicine, University of Indonesia, Dr. Cipto Mangunkusumo Hospital, Jakarta, \\ Indonesia; '2Department of Internal Medicine, Faculty of Medicine, University of Indonesia, Dr. Cipto Mangunkusumo Hospital, \\ Jakarta, Indonesia
}

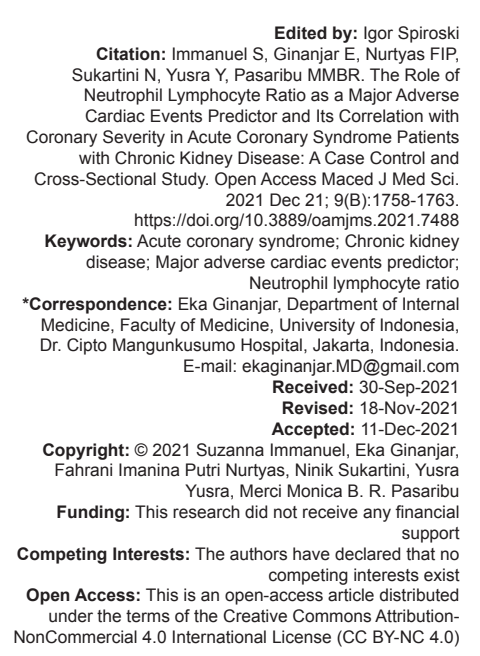

\begin{abstract}
BACKGROUND: Acute coronary syndrome (ACS) patients with chronic kidney disease (CKD) are known to have a higher risk of mortality compared to ACS patients without CKD. In ACS patients with CKD, chronic inflammation plays an important role in morphological and functional changes in endothelial cells, resulting in atherosclerosis acceleration associated with coronary severity that leads to an increase in major adverse cardiac events (MACE).

AIM: Therefore, this study aims to determine the role of neutrophil lymphocyte ratio (NLR) as a predictor of MACE and its correlation with coronary severity in ACS patients with CKD.

METHODS: The study was conducted at National General Hospital Cipto Mangunkusumo Jakarta, Indonesia in October to November 2019. We used quota sampling with two designs study. First, a nested case control study was conducted with a total of 59 ACS patients with CKD: 31 subjects who had experienced MACE as a case group and 28 subjects who had not experienced MACE as a control group. Second, a correlative study with a cross-sectional approach was undertaken.

RESULTS: There was no significant difference or relationship between NLR and MACE $(p>0.05 ;$ OR $=2.16[95 \%$ $\mathrm{Cl}=0.63-7.51]$ ), also no correlation between NLR and coronary severity degree assessed using the Gensini score $(r=0.10 ; p=0.474)$.

CONCLUSION: NLR can not predict MACE in ACS patients with CKD nor be employed interchangeably with the Gensini score in assessing coronary severity in ACS patients with CKD.
\end{abstract}

\section{Introduction}

Acute coronary syndrome (ACS), which involves the acute symptoms of coronary heart disease (CHD), is one of the most common causes of mortality worldwide [1], [2]. In Indonesia, the World Health Organization reports 652,050 deaths caused by cardiovascular disease accounting for $35 \%$ of all deaths due to non-communicable diseases [2]. Chronic kidney disease (CKD), on the other hand, involves a set of symptoms associated with abnormal kidney function and/or decreased glomerular filtration rate, which can be related to increased atherogenesis. Since the risk factors that can trigger CKD can also can trigger ACS, these conditions can affect and worsen each other [3]. ACS patients with CKD are known to have a higher risk of mortality compared to ACS patients without CKD. Every year about $9 \%$ of deaths due to CHD involve CKD, a statistic that is 10-20 times higher than the rate for the general population [4]. In ACS patients with CKD, the chronic inflammatory process plays an important role in the morphological and functional changes of endothelial cells, resulting in accelerated atherosclerosis associated with coronary severity that leads to an increase in major adverse cardiac events (MACE) [5], [6], [7].

Total leukocyte count as an inflammation marker has become the focus of research over the past two decades [8]. Neutrophils, which are part of the leukocyte count, are known to have an important role in the progression and instability of atherosclerotic plaque that triggers ACS. Neutrophils are activated at the time of ischemic event, gather in the ischemic area, then produce reactive oxygen species (ROS). These can aggravate myocardial ischemic conditions and release proteolytic enzymes that damage the surrounding myocytes and affect the stability of the fibrous capsule, 
which then triggers rupture of the plaque [9], [10]. Lymphopenia also occurs in ACS due to abnormalities of $T$ regulator lymphocytes during the acute phase associated with atherosclerotic plaque instability [11]. Based on this pathophysiology, an increase in neutrophil counts and a decrease in lymphocyte counts is related to the progression of ACS. Therefore, neutrophil lymphocyte ratio (NLR) is considered to be more predictive in determining the outcomes for ACS patients compared to the total count of leukocytes and even compared to neutrophil or lymphocyte itself [12].

Since NLR is obtained from a leukocyte count widely available in routine applications, it could be a potential tool for predicting ACS patient's outcomes, such as MACE [8]. Unlike other inflammatory markers, NLR has affordable and less invasive laboratory examination options. To date, NLR studies relating to cardiovascular and renal failure have been limited to the role or effect of NLR in either ACS patients or CKD patients. There are no studies on the role of NLR as a predictor of MACE and its correlation with coronary severity in ACS patients with CKD. In addition, there has been no consensus on the standard value of the cut-off point for NLR in determining MACE. The aim of this study is to know the role of NLR as the predictor of MACE and its correlation with the coronary severity in ACS patients with CKD.

\section{Methods}

This study employed two designs. First, a nested case control design was used with subjects experiencing MACE as a case group and subjects not experiencing MACE as a control group. In addition, a correlative design with a cross-sectional approach was employed. This research using secondary data derived from the electronic health records of Dr. Cipto Mangunkusumo Hospital, Jakarta, from January to October 2018 and was an advanced analysis based on previous research by Ginanjar et al. [13] The study received approval from the Ethics Committee of the Faculty of Medicine of the University of Indonesia (document number: 0128/UN2.F1/ETIK/2018).

The research subjects were patients in Dr. Cipto Mangunkusumo Hospital, Jakarta, who fulfilled the following research criteria: (1) ACS patients who had undergone coronary angiography and were diagnosed with CKD; (2) did not have severe comorbidities, including acute stroke, hepatic cirrhosis, chronic inflammatory disease, sepsis, autoimmune disease, and malignancy; and (3) were not undergoing chronic hemodialysis. In addition, only subjects for whom there was differential leukocyte count data within a maximum 3 days after hospital admission were included in the study [14]. The samples were excluded if there are severe comorbidities, underwent chronic hemodialysis, pregnant or breastfeeding mother, and incomplete medical record.

A minimum sample size of 54 was required using the quota sampling technique to minimize bias. NLR values were obtained from differential leukocyte counts that were part of a complete hematology examination, which was conducted with Sysmex XN-2000 hematology analyzer at Central Laboratory of the Clinical Pathology Department of Dr. Cipto Mangunkusumo Hospital, Jakarta. The Sysmex $\mathrm{XN}-2000$ hematology analyzer is a combination hematology system with two analytical modules that can process 200 samples per hour. NLR calculation was done manually using the following formula:

\section{$\mathrm{NLR}=\frac{\text { Total absolute count of neutrophil }(/ \mu \mathrm{L})}{\text { Total absolute count of lymphocyte }(/ \mu \mathrm{L})}$}

Data analysis were performed using SPSS version 20. The characteristics of the research subjects were presented descriptively. Analysis of the relationship between NLR and MACE was measured using bivariate analysis. Multivariate analysis was not performed in this study. The correlation between NLR and Gensini scores was tested with the Spearman rank method.

\section{Results}

\section{Subject characteristics}

In total, there were 117 subjects included in the previous research of Ginanjar et al. [13] However, 58 subjects did not meet the inclusion criteria for this study: 5 subjects had differential count data from more than 3 days after hospital admission and 53 subjects did not have differential count data. A total of 59 subjects met the inclusion criteria and were grouped based on MACE: 31 subjects for the case group and 28 subjects for the control group. In this study, the minimum sample size needed was fulfilled. Subject characteristics can be seen in Table 1.

\section{Relationship between NLR and MACE in ACS patients with CKD}

A bivariate analysis (Table 2) was performed for MACE and the main independent variable (NLR) as well as for MACE and the other independent variables (risk factors suspected to be confounding factors for MACE) in this study.

\section{Correlation between NLR and Gensini Score}

In this study, no correlation was found between NLR and the Gensini score $(r=0.10 ; p=0.474)$. The 
Table 1: Clinical characteristics of subjects

\begin{tabular}{|c|c|c|c|}
\hline \multirow[t]{2}{*}{ Characteristic } & \multicolumn{2}{|l|}{ MACE } & \multirow[t]{2}{*}{ Total $(n=59)$} \\
\hline & Yes $(n=31)$ & No $(n=28)$ & \\
\hline \multicolumn{4}{|l|}{ Sex } \\
\hline Male & $25(80.6)$ & $21(75)$ & $46(78)$ \\
\hline Female & $6(19.4)$ & $7(25)$ & $13(22)$ \\
\hline Age, years & $60.68 \pm 12.27$ & $58.11 \pm 8.07$ & $59.46 \pm 10.48$ \\
\hline \multicolumn{4}{|l|}{ Body mass index } \\
\hline$>27 \mathrm{~kg} / \mathrm{m}^{2}$ & $8(25.8)$ & $7(25)$ & $15(25.4)$ \\
\hline$<27 \mathrm{~kg} / \mathrm{m}^{2}$ & $23(74.2)$ & $21(75)$ & $44(74.6)$ \\
\hline \multicolumn{4}{|l|}{ ACS } \\
\hline STEMI & $14(45.2)$ & $18(64.3)$ & $32(54.2)$ \\
\hline NSTEMI & $6(19.4)$ & $6(21.4)$ & $12(20.3)$ \\
\hline UAP & $11(35.5)$ & $4(14.3)$ & $15(25.4)$ \\
\hline \multicolumn{4}{|l|}{ Risk factors } \\
\hline DM & $9(29)$ & $14(50)$ & $23(39)$ \\
\hline Dyslipidemia & $7(22.6)$ & $9(32.1)$ & $16(27.1)$ \\
\hline Hypertension & $23(74.2)$ & $17(60.7)$ & $40(67.8)$ \\
\hline Smoking & $18(58.1)$ & $16(57.1)$ & $34(57.6)$ \\
\hline \multicolumn{4}{|l|}{ Stage of CKD } \\
\hline $1-2$ & $12(38.7)$ & $14(50)$ & $26(44.1)$ \\
\hline $3 a-3 b$ & $8(25.8)$ & $11(39.3)$ & 19 (32.2) \\
\hline $4-5$ & $11(35.5)$ & $14(23.7)$ & $14(23.7)$ \\
\hline \multicolumn{4}{|c|}{ Coronary severity (Gensini Score) } \\
\hline Mild - moderate & $4(12.9)$ & $4(14.3)$ & $8(13.6)$ \\
\hline Severe & $27(87.1)$ & $24(85.7)$ & $51(86.4)$ \\
\hline \multicolumn{4}{|l|}{ Hematological results } \\
\hline Hemoglobin ( $\mathrm{g} / \mathrm{dL})$ & $12.26 \pm 2.54$ & $11.53 \pm 2.31$ & $12.34 \pm 2.42$ \\
\hline Platelet $\left(10^{3} / \mu \mathrm{L}\right)$ & 265 (127) & $261(106.5)$ & $262(115)$ \\
\hline Leukocyte $\left(10^{3} / \mu \mathrm{L}\right)$ & $12.4(6.69)$ & $10.78(5.42)$ & $11.5(6.68)$ \\
\hline Basophil (\%) & $0.3(0.4)$ & $0.3(0.3)$ & $0.3(0.3)$ \\
\hline Eosinophil (\%) & $1.4(4.5)$ & $0.85(3.8)$ & $1.4(4.3)$ \\
\hline Neutrophil (\%) & $75.47 \pm 11.02$ & $72.39 \pm 9.19$ & $74 \pm 10.23$ \\
\hline Lymfocyte (\%) & $14 \pm 7.65$ & $17.09 \pm 5.87$ & $15.47 \pm 6.98$ \\
\hline Monocyte (\%) & $6.84 \pm 3.07$ & $7.55 \pm 3.2$ & $7.18 \pm 3.13$ \\
\hline NLR & $4.82(7.39)$ & $4.35(3.23)$ & $4.6(3.68)$ \\
\hline
\end{tabular}

distribution of NLR based on the degree of coronary severity assessed by the Gensini score can be seen in Table 3.

\section{Discussion}

The majority of the subjects were male (46 subjects, 78\%). These results are in line with research by Ghaffari et al. indicating that there are more male $(82.5 \%)$ than female ACS patients, even in different populations and study locations [14]. This is related to differences in risk factor profiles based on sex, since endogenous estrogen is protective in women. It has been proven that after menopause, ACS incidence in women increases rapidly and is proportional to the incidence in men [15]. This study accords with this theory since the mean age of the male participants was $58.63 \pm 9.72$ years, and for female, the mean age was $62,38 \pm 12.84$ years.

The severity of CKD accompanying ACS in this study was grouped into stage $1-2$, stage $3 a-3 b$, and stage 4-5. The highest incidence of MACE was found in subjects of the stage 1-2 (38.7\%) group, followed by the stage $4-5(35.5 \%)$ group, and the stage $3 a-3 b(25.8 \%)$ group. This is not in accordance with Bae et al.'s reasearch, which found that in line with the severity of CKD, there was an increase in the incidence of MACE in ACS patients with CKD. This result is likely due to differences in the population of study subjects, since theirs involved subjects who undergoing chronic hemodialysis, whereas in this study, the subjects were not undergoing chronic hemodialysis [4]. In addition, the proportion of subjects in the stage 1-2 group in this study was higher than that in the other groups, totaling 26 subjects $(44.1 \%)$ and there were only 14 subjects $(23.7 \%)$ in stage $4-5$ group.

Based on hematologic examination results, the median leukocytes of all subjects were 11,500 cells/ $\mu \mathrm{L}$. The median leukocytes of subjects experiencing MACE and not experiencing MACE were 12,400 cells/ $\mu \mathrm{L}$ and 10,780 cells/ $\mu \mathrm{L}$, respectively. These results indicate the presence of mild leukocytosis in almost all subjects. This relates to the pathophysiology of ACS involving various inflammatory factors, including leukocytes, therefore mild leukocytosis can occur in patients with

Table 2: Relationship between independent variables and MACE in ACS patients with CKD

\begin{tabular}{|c|c|c|c|c|c|c|}
\hline \multirow[t]{2}{*}{ Independent variables } & \multicolumn{2}{|l|}{ MACE } & \multirow[t]{2}{*}{$\mathrm{p}$-value } & \multirow[t]{2}{*}{ Odds ratio } & \multicolumn{2}{|c|}{$95 \% \mathrm{Cl}$} \\
\hline & Yes & No & & & Low & High \\
\hline \multicolumn{7}{|l|}{ NLR } \\
\hline High $(>3.62)$ & $23(74.2)$ & $16(57.1)$ & 0.167 & 2.16 & 0.63 & 7.51 \\
\hline Low $(<3.62)$ & $8(25.8)$ & $12(42.9)$ & & & & \\
\hline \multicolumn{7}{|c|}{ Coronary severity (Gensini Score) } \\
\hline Severe & $27(87.1)$ & $24(85.7)$ & 0.877 & 0.89 & 0.20 & 3.95 \\
\hline Mild-moderate & $4(12.9)$ & $4(14.3)$ & & & & \\
\hline \multicolumn{7}{|l|}{ Sex } \\
\hline Male & $25(80.6)$ & $21(75)$ & 0.601 & 1.39 & 0.40 & 4.78 \\
\hline Female & $6(19.4)$ & $7(25)$ & & & & \\
\hline \multicolumn{7}{|l|}{ Age group } \\
\hline $37-59$ years & $16(51.6)$ & $17(60.7)$ & 0.482 & 0.69 & 0.21 & 2.20 \\
\hline $60-84$ years & $15(48.4)$ & $11(39.3)$ & & & & \\
\hline \multicolumn{7}{|l|}{ Obesity } \\
\hline Yes & $8(25.8)$ & $7(25)$ & 0.943 & 1.04 & 0.32 & 3.38 \\
\hline No & $23(74.2)$ & $21(75)$ & & & & \\
\hline \multicolumn{7}{|l|}{ Diabetes melitus } \\
\hline Yes & $9(29)$ & $14(50)$ & 0.099 & 0.41 & 0.14 & 1.19 \\
\hline No & $22(71)$ & $14(50)$ & & & & \\
\hline \multicolumn{7}{|l|}{ Dyslipidemia } \\
\hline Yes & $7(22.6)$ & $9(32.1)$ & 0.409 & 0.62 & 0.19 & 1.96 \\
\hline No & $24(77.4)$ & $19(67.9)$ & & & & \\
\hline \multicolumn{7}{|l|}{ Hipertension } \\
\hline Yes & $23(74.2)$ & $17(60.7)$ & 0.269 & 1.86 & 0.62 & 5.62 \\
\hline No & $8(25.8)$ & $11(39.3)$ & & & & \\
\hline \multicolumn{7}{|l|}{ Smoking } \\
\hline Yes & $18(58.1)$ & 16 (57.1) & 0.943 & 1.04 & 0.37 & 2.92 \\
\hline No & $13(41.9)$ & $12(42.9)$ & & & & \\
\hline \multicolumn{7}{|l|}{$\beta 2$-microglobulin level } \\
\hline High risk & $23(74.2)$ & $18(64.3)$ & 0.409 & 0.63 & 0.21 & 1.91 \\
\hline Low risk & $8(25.8)$ & $10(35.7)$ & & & & \\
\hline
\end{tabular}


ACS [5], [14]. The median NLR in the case group (4.82) was very similar to that in the control group (4.35) because the subject's mean neutrophils were still in the normal range at $75.47 \%$ in this study.

Table 3: Distribution of NLR based on the degree of coronary severity by gensini score

\begin{tabular}{ll}
\hline Coronary severity (gensini score) & NLR \\
\hline Mild - Moderate $(<20)$ & $6.62(1.84-17.47)$ \\
Severe $(>20)$ & $4.55(2.09-86.45)$ \\
\hline
\end{tabular}

The results of this study's analysis showed no statistically significant difference between the NLR values in the case group and those the control group $(p=0.167)$. There was also no statistically significant relationship between NLR and MACE (OR = 2.16 [95\% $\mathrm{Cl}=0.63-7.51])$. Even so, descriptively, the trend of high NLR (>3.62) was found to be more common in the case group $(74.2 \%)$ than in the control group, so this value still has the potential to be able to predict MACE.

The NLR results, which tended to be lower and not statistically significant in this study, were not in accordance with a number of previous studies that found the NLR results tended to be high and statistically significant (Table 4).

Other studies showed more meaningful results because the sampling was carried at the same time, In this study, however the sampling time varied between 1 and 3 days after hospitalization. NLR values also tended to be high in other studies because the differential counts were taken during a neutrophil recruitment peak: less than $1 \mathrm{~h}$ after being admitted to the hospital in Tamhane et al.'s, within $12 \mathrm{~h}$ in Han et al.'s, as well as within $24 \mathrm{~h}$ in Sawant et al.'s and Rich et al.'s study [12], [16], [18], [19]. In the first 24-72 h after hospitalization, a significant neutrophilia can be found and thereafter, a gradual decrease occurs [14]. The neutrophil recruitment at the onset of ACS contributes greatly to the modulation of NLR, especially at the beginning of ACS [20], [21].

At the time of ACS onset, the acute inflammation that occurs causes an increase in neutrophils. Neutrophils mediate the acute inflammatory response by releasing proinflammatory cytokines, such as metabolic arachidonic acid, platelet factor, ROS, myeloperoxidase, and matrix metalloproteinase [9], [10], [22], [23]. This is followed by relative lymphopenia, which is thought to be caused by increased endogenous cortisol in response to stress triggered by infarction conditions [18]. Blum et al. showed a decrease in T lymphocyte cells correlated with a decrease in ejection fraction that could be a marker of infarction [21]. The studies of Flego et al. and Ommen et al. also showed that in the acute phase of ACS, there is a dysregulation of $T$ regulator lymphocytes. This causes a decrease in their number and function, leading to activation of autoaggressive $T$ cells that secrete interferon- $\gamma$ that will exacerbate the inflammatory cascade [24], [25].

Differential leukocyte count is not a routine examination requested by clinicians for ACS patients either with or without CKD. Therefore, the majority of the subjects in this study were examined for differential count on the $3^{\text {rd }}$ day after hospital admission, making the possibility of the subject having pharmacologic therapy very high. As a result, the neutrophil mean in this study was likely lower, producing a lower NLR. In Akpek et al.'s study, the NLR results were lower than this study, with statistically significant $p$ values, since the differential count was taken after the $\mathrm{PCl}$ procedure. Under these conditions, the neutrophil recruitment had subsided, so the NLR was low [17]. This supports the theory that the NLR results are low in this study because the subjects may have received therapy for ACS. Another theory is that the low neutrophil yield was probably because the majority of subjects were male. According to Gwak et al., men have a lower proportion of neutrophils than women, so they appear to have a lower NLR. This is associated with cortisol responses to physical stress in men, which are lower than those in women [26].

Another factor that may have caused meaningless NLR results in this study is that there was a higher proportion of subjects within the CKD stage 1-2 group (26 subjects, $44.1 \%$ ) than in the other groups, meaning MACE occurred primarily in the stage 1-2 group (38.7\%). A comparison of NLR results with those of other studies on CKD conditions can be found in Table 5.

Solak et al. explained that inflammation occurrs from the early stages of CKD, and increased inflammation in CKD is associated with poor cardiovascular outcomes [27]. This indicates that chronic inflammation occurrs in CKD when the peak of neutrophil recruitment is no longer taking place. This condition causes the NLR value in CKD to be lower. This finding similar to those Nelly et al.'s study [7]. The subjects in the current study were ACS patients with CKD, so the NLR values obtained were lower than those in other studies that examined subjects with ACS alone, and the NLR values obtained were higher than those in other studies that examined subjects with CKD alone. As this study is the first to assess the role

Table 4: Comparison of this study results with other similar research in ACS patient

\begin{tabular}{|c|c|c|c|c|c|}
\hline Study & NLR & Leukocyte $\left(10^{3} / \mu \mathrm{L}\right)$ & Neutrophil (\%) & Lymphocyte (\%) & $\mathrm{p}$-value \\
\hline This study & $4.82(7.39)$ & $12.4(6.69)$ & $75.47 \pm 11.02$ & $14 \pm 7.65$ & 0.154 \\
\hline Tamhane et al. [17] & $9.10(7.27)$ & $11(6)$ & $95(52)$ & $10(6)$ & $<0.001$ \\
\hline Han et al. [18] & $11.86 \pm 9.34$ & $13.80 \pm 4.47$ & - & - & 0.036 \\
\hline Sawant et al. [12] & 7.4 & $14.68 \pm 7.48$ & $94.1 \pm 6.28$ & $9.8 \pm 5.2$ & $<0.001$ \\
\hline Kaya et al. [15] & $6.8 \pm 2.5$ & - & $80.3 \pm 5.9$ & $12.8 \pm 3.2$ & $<0.001$ \\
\hline Akpek et al. [16] & $4.6 \pm 1.7$ & $12.5 \pm 5$ & $73.7 \pm 8.2$ & $18.1 \pm 5.6$ & $<0.001$ \\
\hline
\end{tabular}


of NLR as a predictor of MACE in ACS patients with CKD, it cannot be compared to other studies that are significantly similar. The hypothesis that NLR values in ACS patients with CKD who experienced MACE were higher than those who had not experienced MACE was not proven in this study.

In this study, no significant correlation was found between NLR and Gensini score $(r=0.10$; $p=0.474)$. These results are slightly different with the study conducted by Chen et al., who got a very weak positive correlation between NLR and Gensini scores $(r=0.065 ; p=0.001)$ [28]. These results may be due to the pathophysiology of coronary severity, which is not only based on the presence of stenosis due to endothelial damage and stiffness, but it can also be caused by the thrombus formation from ruptured plaque which then forms an occlusion in the coronary vessels. Occlusion of the coronary vessels can occur in part or in total from one or more coronary arteries or their branches [1], [13].

Table 5: Comparison of this study results with other similar research in CKD patient

\begin{tabular}{lll}
\hline Study & NLR & p-value \\
\hline This study & $4.51(1.84-12.32)$ & \\
Stage 1-2 & $4.33(2.09-29.63)$ & 0.159 \\
Stage 3a-3b & $5.43(2.68-86.45)$ & \\
Stage 4-5 & & \\
Solak et al. [24] & $2.7(0.6-7.23)$ & 0.04 \\
Stage 3 & $2.76(1.32-7.14)$ & \\
Stage 4 & $3(0.98-10.33)$ & 0.027 \\
Stage 5 & $1.96 \pm 0.91$ & \\
Nelly et al. [7] & $1.87 \pm 0.6$ & \\
Pre-HD & $2.11 \pm 0.83$ & \\
Post-HD1 & & \\
Post-HD2 &
\end{tabular}

In general, STEMI is caused by a total blockage in the main coronary arteries in one location. Leukocyte recruitment, on the other hand, occurs in response to inflammation, and the increase in leukocytes will be directly proportional to the severity of the infarction area. The Gensini score for total STEMI will be high, but neutrophil recruitment that occurs in only one location causes low NLR results. While non-STEMI lesion's is more complex because it involves more than three blood vessels, resulting in increased recruitment of leukocytes to various inflammatory sites, and produces high NLR but does not correlate with low Gensini scores [28]. Based on this theory, high NLR may indicate the role of inflammation, but it is not sufficient to assess coronary severity in patients with ACS in general. There is no correlation between NLR and the Gensini score, so the two parameters cannot used interchangeably. In this study, the hypothesis that NLR has a strong positive correlation with Gensini scores in determining coronary severity in ACS patients with CKD was not proven.

This study is a nested case control study that used secondary data from previous study, thus researchers are not free to determine the number of cases and controls because of the availability of existing data. The examination of leukocyte count is not a routine examination requested by clinicians for ACS patients with or without CKD. This causes many subjects could not be included in this study. However, this study provides a new insight in relationship between NLR and MACE in ACS patients with CKD.

\section{Conclusion}

NLR can neither predict MACE nor replace Gensini scores for assessing coronary severity in ACS patients with CKD.

\section{Acknowledgment}

The authors are grateful to all the staffs of the Clinical Pathology Department of Dr. Cipto Mangunkusumo Hospital and Universitas Indonesia.

\section{References}

1. Scirica BM, Morrow DA. ST-elevation myocardial infarction: Pathology, pathophysiology, and clinical features. In: Mann DL, Zipes DP, Libby P, Bonow RO, Braunwald E, editors. Braunwald's Heart Disease a Text Book of Cardiovascular Medicine. $10^{\text {th }}$ ed., Ch. 51. Philadelphia, PA: Elsevier, Saunders; 2015. p. 444.

2. World Health Organization. Noncommunicable Disease Country Profiles 2018. Geneva, Switzerland: World Health Organization; 2018. Available from: https://www.apps.who.int/ iris/handle/10665/274512. [Last accessed on 2021 Dec 29].

3. Kazancioglu R. Risk factors for chronic kidney disease: An update. Kidney Int Suppl (2011). 2013;3(4):368-71. https://doi. org/10.1038/kisup.2013.79

PMid:25019021

4. Bae EH, Lim SY, Cho KH, Choi JS, Kim CS, Park JW, et al. GFR and cardiovascular outcomes after acute myocardial infarction: Results from the Korea acute myocardial infarction registry. Am J Kidney Dis. 2012;59(6):795-802. https://doi.org/10.1053/j. ajkd.2012.01.016

PMid:22445708

5. Kounis NG, Soufras GD, Tsigkas G, Hahalis G. White blood cell counts, leukocyte ratios, and eosinophils as inflammatory markers in patients with coronary artery disease. Clin Appl Thromb Hemost. 2015;21(2):139-43. https://doi. org/10.1177/1076029614531449

PMid:24770327

6. Jimbo R, Shimosawa T. Cardiovascular risk factors and chronic kidney disease-FGF23: A key molecule in the cardiovascular disease. Int J Hypertens. 2014;2014:381082. https://doi. org/10.1155/2014/381082

PMid:24678415

7. Nelly N, Widaningsih $\mathrm{Y}$, Mangarengi F. Neutrophil lymphocyte ration value and lymphocyte thrombocyte ration in chronic kidney disease patients before and after hemodialysis [Nilai rasio netroil limfosit dan rasio trombosit limfosit pada pasien 
chronic kidney disease sebelum dan setelah hemodialisa]. Intisari Sains Medis. 2019;10:230-4.

8. Ahmad TM, Afzal MN. Assessment of differential leukocyte count in patients with acute coronary syndrome. J Pak Med Assoc. 2010;60(7):548-51.

\section{PMid:20578604}

9. Ikonomidis I, Michalakeas CA, Parissis J, Paraskevaidis I, Ntai K, Papadakis I, et al. Inflammatory markers in coronary artery disease. Biofactors. 2012;38(5):320-8. https://doi. org/10.1002/biof.1024

PMid:22628054

10. Soehnlein O. Multiple roles for neutrophils in atherosclerosis. Circ Res. 2012;110(6):875-88. https://doi.org/10.1161/ circresaha.111.257535

PMid:22427325

11. Caligiuri G, Nicoletti A. Lymphocyte responses in acute coronary syndromes: Lack of regulation spawns deviant behaviour. Eur Heart J. 2006;27(21):2485-6. https://doi.org/10.1093/eurheartj/ ehl284

PMid:17020888

12. Sawant AC, Adhikari P, Narra SR, Srivatsa SS, Mills PK, Srivatsa SS. Neutrophil to lymphocyte ratio predicts short and long term mortality following revascularization therapy for ST elevation myocardial infarction. Cardiol J. 2014;21(5):500-8. https://doi.org/10.5603/cj.a2013.0148

PMid:24142685

13. Ginanjar E, Alwi I, Lydia A, Immanuel S, Yamin M, Indrajaya T, et al. The association of $\beta 2$-microglobulin and fibroblast growth factor 23 with major adverse cardiac event in acute coronary syndrome patients with chronic kidney disease. Acta Med Indones. 2021;53(1):5-12.

PMid:33818401

14. GhaffariS, Nadiri M, Pourafkari L, Sepehrvand N, MovasagpoorA, Rahmatvand $\mathrm{N}$, et al. The predictive value of total neutrophil count and neutrophil/lymphocyte ratio in predicting in-hospital mortality and complications after STEMI. J Cardiovasc Thorac Res. 2014;6(1):35-41. https://doi.org/10.5681/jcvtr.2014.007 PMid:24753830

15. Srichaiveth B, Ruengsakulrach $P$, Visudharom $K$, Sanguanwong S, Tangsubutr W, Insamian P. Impact of gender on treatment and clinical outcomes in acute ST elevation myocardial infarction patients in Thailand. J Med Assoc Thai. 2007;90 Suppl 1:65-73.

PMid:18431888

16. Kaya MG, Akpek M, Lam YY, Yarlioglues M, Celik T, Gunebakmaz O, et al. Prognostic value of neutrophil/lymphocyte ratio in patients with STelevated myocardial infarction undergoing primary coronary intervention: A prospective, multicenter study. Int J Cardiol. 2013;168(2):1154-9. https://doi.org/10.1016/j. ijcard.2012.11.074

PMid:23219132

17. Akpek M, Kaya MG, Lam YY, Sahin O, Elcik D, Celik T, et al. Relation of neutrophil/lymphocyte ratio to coronary flow to in-hospital major adverse cardiac events in patients with ST-elevated myocardial infarction undergoing primary coronary intervention. Am J Cardiol. 2012;110(5):621-7. https://doi. org/10.1016/j.amjcard.2012.04.041

PMid:22608360

18. Tamhane UU, Aneja S, Montgomery D, Rogers EK, Eagle KA,
Gurm HS. Association between admission neutrophil to lymphocyte ratio and outcomes in patients with acute coronary syndrome. Am J Cardio. 2008;102(6):653-7. https://doi. org/10.1016/j.amjcard.2008.05.006

PMid: 18773982

19. Han YC, Yang TH, Kim DI, Jin HY, Chung SR, Seo JS, et al. Neutrophil to lymphocyte ratio predicts long-term clinical outcomes in patients with ST-segment elevation myocardial infarction undergoing primary percutaneous coronary intervention. Korean Circ J. 2013;43(2):93-9. https://doi. org/10.4070/kcj.2013.43.2.93

PMid:23508782

20. Maugeri N, Rovere-Querini P, Evangelista V, Godino C Demetrio M, Baldini M, et al. An intense and short-lasting burst of neutrophil activation differentiates early acute myocardial infarction from systemic inflammatory syndromes. PLoS One. 2012;7(6):e39484. https://doi.org/10.1371/journal. pone.0039484

PMid:22761804

21. Blum A, Sheiman J, Hasin Y. Leukocytes and acute myocardial infarction. Isr Med Assoc J. 2002;4(11):1060-5.

PMid: 12489507

22. Ruslie RH, Ramayani OR, Darmadi D, Siregar GA. Oxidative stress markers in initial therapy and remission of nephrotic syndrome and serum malondialdehyde level predictor from routine laboratory test. Med Glas (Zenica). 2021;18(1):90-5. https://doi.org/10.17392/1192-21

PMid:32815672

23. Sitepu RR, Darmadi D, Siregar GA. Correlation between TNF- $\alpha$ and degree of gastritis. Indones J Gastroenterol Hepatol Dig Endosc. 2018;19:16-9. https://doi.org/10.24871/191201816-19

24. Flego D, Liuzzo G, Weyand CM, Crea F. Adaptive immunity dysregulation in acute coronary syndromes: From cellular and molecular basis to clinical implications. J Am Coll Cardiol. 2016;68(19):2107-17. https://doi.org/10.1016/j.jacc.2016.08.036 PMid:27810051

25. Ommen SR, Gibbons RJ, Hodge DO, Thomson SP. Usefulness of the lymphocyte concentration as a prognostic marker in coronary artery disease. Am J Cardiol. 1997;79(6):812-4. https://doi.org/10.1016/s0002-9149(96)00878-8 PMid:9070569

26. Gwak MS, Choi SJ, Kim JA, Ko JS, Kim TH, Lee SM, et al. Effects of gender on white blood cell populations and neutrophillymphocyte ratio following gastrectomy in patients with stomach cancer. J Korean Med Sci. 2007;22:S104-8. https://doi. org/10.3346/jkms.2007.22.S.S104

PMid:17923734

27. Solak Y, Yilmaz MI, Sonmez A, Saglam M, Cakir E, Unal HU, et al. Neutrophil to lymphocyte ratio independently predicts cardiovascular events in patients with chronic kidney disease. Clin Exp Nephrol. 2013;17(4):532-40. https://doi.org/10.1007/ s10157-012-0728-x PMid:23180042

28. Chen J, Chen MH, Li S, Guo YL, Zhu CG, Xu RX, et al Usefulness of the neutrophil-to-lymphocyte ratio in predicting the severity of coronary artery disease: A Gensini score assessment. J Atheroscler Thromb. 2014;21(12):1271-82. https://doi.org/10.5551/jat.25940

PMid:25069816 